\title{
A Study on the Preferred Real-Ear Insertion Gain of Multi-Channel Hearing Aid for the Korean with Sensorineural Hearing Loss
}

\author{
Eojini Bang ${ }^{1}$, Kyoungwon Lee K, $^{1,2}$ \\ 'Department of Audiology and Speech-Language Pathology, Hallym University of Graduate Studies, Seoul, Korea \\ ${ }^{2}$ HUGS Center for Hearing and Speech Research, Seoul, Korea
}

\author{
Received: February 3, 2020 \\ Revised: March 12, 2020 \\ Accepted: March 19, 2020 \\ Correspondence: \\ Kyoungwon Lee, PhD \\ Department of Audiology and \\ Speech-Language Pathology, \\ Hallym University of Graduate Studies, \\ 427 Yeoksam-ro, Gangnam-gu, \\ Seoul 06197, Korea \\ Tel: +82-2-2051-4951 \\ Fax: +82-2-3453-6618 \\ E-mail: leekw@hallym.ac.kr
}

\begin{abstract}
Purpose: This study aimed to compare the preferred real-ear insertion gain for Korean (PREIG-K) wearing multi-channel hearing aid with the National Acoustics Laboratories-Non-Linear version 2 (NAL-NL2; National Acoustic Laboratories) gains in order to develop Korean hearing aid fitting formula. Methods: A total of thirty one (62 ears) Korean hearing aid users were included in this study. All subjects wore in-the-canal or custom hearing aids in both ears. Individual hearing aid fitting procedures involved to adjust the gains for 50,65 , and $80 \mathrm{~dB}$ sound pressure level of speech across low, high, and wideband frequency bands based on participant's subjective responses. In addition, only the high frequency bands of $1 \mathrm{kHz}$ or more of the PREIG-K were re-adjusted to be the same as NAL-NL2 gain and then the word recognition scores (WRSs) were compared before and after the adjusting gain. Results: The results showed that the PREIG-K increased up to $1.5 \mathrm{kHz}$ with the maximum amount, then the PREIG-K decreased across the frequencies. For all half octave frequencies, the PREIG-Ks were substantially less than the NAL-NL2. When the PREIG-K of high frequencies were re-adjusted same as the NAL-NL2 gains, the WRSs of the PREIG-K were not significantly different before and after gain adjustment. The slopes up to $1.5 \mathrm{kHz}$ frequencies of the PREIG-K were steeper than the slopes of NAL-NL2 gain, however similar to the slope of manufactures' fitting formulae. Conclusion: The development of an effective hearing aid fitting formula for improving the communication abilities of hearing-impaired Korean will require further experiments considering the language, physical characteristics, and word recognition used by Koreans.
\end{abstract}

Key Words: Hearing aid fitting formula, Multi-channel hearing aid, Preferred gain, Real-ear insertion gain, Sensorineural hearing loss.

\section{INTRODUCTION}

청력역치레벨(hearing threshold level, HTL)의 증가로 인해 역동 범위가 좁은 감각신경성 난청은 입력 음압레벨(sound pressure level, SPL)이 증가함에 따라 이득이 감소하는 비선형 증폭 시스템(nonlinear amplification system)의 사용이 효과 적이다(Blamey \& Martin, 2009; Jenstad et al., 1999). 비선형 증폭 시스템에서 조절하는 전기음향적 매개변수(parameter)는 음향이득 또는 주파수반응곡선(frequency response curve)을 비롯하여 압축역치(compression threshold)와 압축비율(compression ratio), 압축시간(attack time)과 해제시간(release time) 등이 있다. HTL에 따라 전기음향적 매개변수를 조절하

(c) This is an Open Access article distributed under the terms of the Creative Commons Attribution Non-Commercial License (https://creativecommons.org/licenses/by-nc/4.0) which permits unrestricted non-commercial use, distribution, and reproduction in any medium, provided the original work is properly cited.
면 HTL과 역동 범위, 신호대잡음비(signal-to-noise ratio), 자 모음비(consonant-to-vowel ratio)를 개선할 수 있으며, 다양 한 환경에서 난청인의 의사소통능력의 개선에 도움을 줄 수 있 다(Jeong \& Lee, 2018; Kim \& Lee, 2019; Lee, 2014; Souza, 2002). 또한 주파수 대역별로 비선형 증폭이 작동하는 다채널 (multi-channel) 증폭 시스템은 한 개의 귀에서 서로 다른 역 동 범위를 개선할 수 있으며, 신호대잡음비, 자모음비, 상향차폐 (upward spread of masking) 등을 단채널(single channel)에 비해 더욱 효과적으로 개선할 수 있다(Yasin \& Plack, 2005; Yund \& Buckles, 1995). 그리고 보청기 관련 연구소 및 제조사 에서는 보청기의 매개변수를 효과적으로 조절하기 위해 보청 기적합공식(hearing aid fitting formula)을 개발하여 사용하 고 있다.

비선형 증폭 시스템의 보청기적합공식은 Fig. 6(Killion \& Fikret-Pasa, 1993), the Independent Hearing Aid Fitting Fo- 
rum (Cox, 1995), the desired sensation level (DSL) input/output (Cornelisse et al., 1995), National Acoustics Laboratories-Non-Linear version 1(NAL-NL1; National Acoustic Laboratories, Sydney, Australia) (Dillon, 1999) 또는 National Acoustics Laboratories-Non-Linear version 2(NAL-NL2; National Acoustic Laboratories) (Keidser et al., 2011), 제조사 의 적합공식 등이 있다. 보청기적합공식은 일반적으로 40 50 $\mathrm{dB}$ SPL의 작은 소리, 60 70 dB SPL의 보통 대화음, 80 90 dB $\mathrm{SPL}$ 의 큰 소리에 대한 이득을 각각 결정하며, 현재까지도 지속 적으로 수정 및 보완 중에 있다.

보청기적합공식의 산출에 영향을 주는 주요 요소들을 살펴 보면 첫째, 기도 및 골도 HTL, 쾌적강도레벨(most comfortable level, MCL), 불쾌강도레벨(uncomfortable level, UCL)을 포함 한 음량 증가(loudness growth) 등의 청지각적 특성이 있다. 둘 째, 대역중요함수(band importance function) (Byrne et al., 2001; Scollie et al., 2005), 어음스펙트럼(Byrne \& Dillon, 1986; Cornelisse et al., 1995; Lee \& Kim, 2011) 등 어음의 특성이 있 다. 셋째, 실이대커플러차(real ear-to-coupler difference), 실이 대다이얼차(real ear-to-dial difference) 등 신체적인 특징이 있 다(Byrne \& Dillon, 1986; Byrne et al., 2001; Cornelisse et al., 1995; Scollie et al., 2005). 이 중에서 어음의 특성을 나타내는 장기평균어음스펙트럼과 대역중요함수에 대해서 살펴보면 Lee et al.(2008), Noh \& Lee(2012)의 연구에서는 한국어의 장기평 균어음스펙트럼은 고주파수와 저주파수 대역의 에너지 차이가 영어에 비해 더 크게 나타났다고 보고하였다. 대역중요함수는 영어의 경우 Northwestern University Auditory Test Number 6(Studebaker et al., 1993)와 Central Institute for the Deaf의 W-22(Studebaker \& Sherbecoe, 1991) 단어, 그리고 hearing in noise test에서 사용하는 문장(Eisenberg et al., 1998)의 대역중 요함수는 $2.0 \mathrm{kHz}$ 부근에서 높게 나타났다고 보고하였다. 그러 나 한국어의 연구에서 Lee \& $\mathrm{Kim}(2012)$ 은 한국어 단음절의 경우 $0.8 \mathrm{kHz}$ 에서 $1.25 \mathrm{kHz}$, Jin et al.(2015)은 한국어 문장은 $1.0 \mathrm{kHz}$ 이하의 저주파수 대역에서 대역중요함수가 높게 나타 났다고 보고하였다. 이 두 가지 요소는 한국어의 음향적 특성에 알맞은 보청기적합공식 개발의 필요성을 시사한다. 한국 난청인 을 위한 보청기적합공식은 Jin et al.(2017)과 Han et al.(2017)이 보고하였다. Jin et al.(2017)은 다채널 보청기 착용 후 난청인의 선호이득을 구하여 NAL-NL2 및 DSL 5.0과 비교하였다. 그 결 과 작은 소리(40 dB SPL), 보통 소리(60 dB SPL), 큰 소리(80 dB SPL) 모두 $0.5 \mathrm{kHz}$ 이하와 $4.0 \mathrm{kHz}$ 이상의 주파수 대역에서 한 국 감각신경성 난청인의 선호이득이 낮게 나타났다. Han et al.(2017)의 연구에서는 압축역치를 $31 \mathrm{~dB}$ SPL과 $61 \mathrm{~dB}$ SPL, 그 리고 해제시간을 $50 \mathrm{~ms}$ 와 $500 \mathrm{~ms}$ 로 변화했을 때 문장인지도를
측정하였으나 유의미한 차이는 나타나지 않았다. 다만 해제시간 이 $50 \mathrm{~ms}$ 일 때 어음명료도는 증가하였다. 하지만 상기의 연구에 서 한국형 보청기적합공식의 검증은 보청기 시제품(proto type of hearing aid)을 이용하여 방음실 내에서 문장청취역치(reception thresholds of sentences), 명료도 및 선호도를 NALNL2 및 DSL 5.0과 비교하여 일상생활에서 이득의 효용성을 확 인하기에는 한계가 있었다.

선행연구에서 장기평균어음스펙트럼의 에너지(Lee et al., 2008; Noh \& Lee, 2012)와 대역중요함수(Jin et al., 2015)는 영 어에 비해 저주파수에서 높게 나타나며, 한국인이 선호하는 음 질은 $2.0 \mathrm{kHz}$ 이상에서 NAL-NL2에 비해 낮게 나타났다(Jin et al., 2017). 이를 토대로 본 연구의 선호실이삽입이득(preferred real-ear insertion gain for Korean, PREIG-K)은 NAL-NL2에 비해 $1.0 \mathrm{kHz}$ 이하와 $2.0 \mathrm{kHz}$ 이상의 주파수에서 실이삽입이득 (real-ear insertion gain, REIG)이 낮게 나타날 것으로 가설을 세웠다. 본 연구에서는 한국 난청인을 위한 새로운 보청기적합 공식 개발에 필요한 자료를 수집하기 위하여 양측에 보청기를 착용한 난청인이 일상생활에서 만족하는 PREIG-K를 확인하 고자 하였다. 구체적인 내용으로는 첫째, 한국 감각신경성 난청 인의 PREIG-K를 구하여 NAL-NL2와 비교하고, 둘째, 신뢰성 을 확인하기 위해 PREIG-K에서 고주파수 대역의 REIG를 NAL-NL2와 같게 조절(modified PREIG-K, M-PREIG-K)했 을 때 PREIG-K와 M-PREIG-K 간에 단어인지도(word recognition score, WRS)의 차이가 나타나는지를 확인하였다. 본 연구의 결과를 통하여 한국 감각신경성 난청인이 착용하는 다 채널 보청기의 효과적인 전기음향적 조절, 그리고 한국 난청인 의 의사소통능력 및 음질의 개선에 효과적인 한국형 보청기적 합공식의 산출에 기초 자료로 활용하고자 하였다.

\section{MATERIALS AND METHODS}

\section{연구 대상}

\section{PREIG-K}

PREIG-K를 확인하기 위해 육안검사 시 외이도 및 고막의 형태가 정상이며, 순음청력검사 시 $0.5 \mathrm{kHz}$ 에서 $4.0 \mathrm{kHz}$ 의 기 도-골도차(air-bone gap)가 $15 \mathrm{~dB}$ 이내인 감각신경성 난청인 31명(남성: 24명, 여성: 7명), 62귀를 대상으로 하였다. 대상자의 평균 연령은 76.8세(범위: 61 89세, 표준편차: 7.37)였으며, 순 음역치 평균(pure-tone threshold average)은 $55.8 \mathrm{~dB} \mathrm{HL}$ (범 위: 26.7 83.3 dB HL, 표준편차: 11.62)이었다(Figure 1). 모든 대상자는 양이에 보청기를 착용하였으며, 착용 기간은 6 개월 이상으로 평균 3.5년(범위: 0.7 20.2년), 하루 평균 착용 시간은 


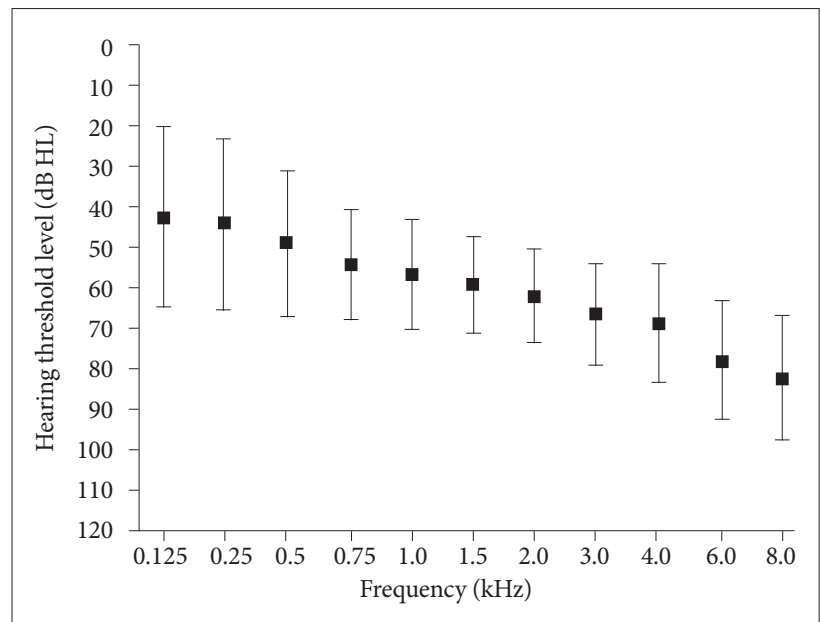

Figure 1. Mean and standard deviation of hearing threshold level of subjects at each $1 / 2$ octave frequencies.

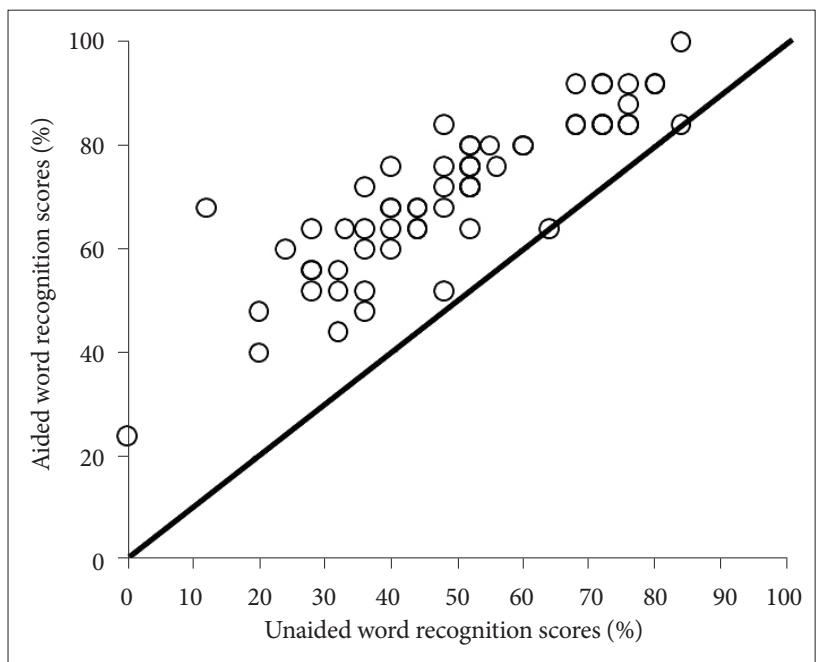

Figure 2. Word recognition scores of unaided with TDH-39 headphone (Telephonics), and aided with hearing aid.

8시간 이상이었다. 대상자의 평균 WRS는 헤드폰 착용 시 $\mathrm{MCL}$ 에서 49.55\%(범위: 0 84\%, 표준편차: 18.97), 보청기를 착 용한 후 음장 스피커(loud speaker)의 정면에서 단음절어를 45 $\mathrm{dB}$ HL로 제시했을 때 70.84\%(범위: 24 100\%, 표준편차: 15.01)였다(Figure 2). 그리고 Korean version of international outcome inventory for hearing aids (K-IOI-HA) (Chu et al., 2012) 점수는 30점 이상으로 평균은 33.6점이었다. 대상자가 착 용한 보청기는 초고막형(invisible-in-the-canal type) 2개, 고 막형(completely-in-the-canal type) 14개, 외이도형(in-thecanal type) 6개, 외이도내수화기형(receiver-in-the-canal type) 보청기가 40 개였다. 사용한 보청기의 형태별 제조사, 채널 의 수 및 수량 등은 Table 1과 같다.
Table 1. Types, manufacturers, numbers of channel, and quantities of hearing aids used in this study

\begin{tabular}{cccc}
\hline Hearing aid type & Manufacturer & No. of channels & Quantity \\
\hline Custom hearing aid & & & \\
IIC & Phonak & 20 & 2 \\
CIC & Beltone & 9 & 2 \\
& Oticon & 6 & 2 \\
& Phonak & $6-20$ & 3 \\
& Widex & $3-10$ & 7 \\
ITC & Oticon & 6 & 1 \\
& Phonak & $12-20$ & 4 \\
BTE & Rexton & 6 & 1 \\
RIC & & & \\
& Oticon & $6-64$ & 16 \\
& Phonak & $6-20$ & 14 \\
& Widex & $6-15$ & 10 \\
\hline
\end{tabular}

BTE: behind-the-ear, IIC: invisible-in-the-canal, CIC: completelyin-the-canal, ITC: in-the-canal, RIC: receiver-in-the-canal

\section{PREIG-K와 M-PREIG-K의 WRS}

PREIG-K와 M-PREIG-K의 WRS를 비교하기 위한 대상 자는 PREIG-K를 확인한 대상자 중에서 협조가 가능한 평균 연령이 76.7세(범위: 71 83세, 표준편차: 4.4)로 총 6명, 12귀를 모집하였다. 대상자의 순음역치 평균은 $55.4 \mathrm{~dB} \mathrm{HL}$ (범위: 31.7 83.3 dB HL, 표준편차: 13.8), WRS의 평균은 39.9\%(범 위: 12 60\%, 표준편차: 16.1)였다(Table 2). 대상자가 착용한 보청기는 6 64 채널의 초고막형이 2개, 외이도내수화기형이 10 개였다.

\section{연구 장비 및 재료}

외이도 및 고막의 육안검사는 이경, 보청기 착용 전 기도 및 골도 HTL과 WRS 평가는 AURICAL Aud (GN Otometrics, Copenhagen, Denmark)와 TDH-39 헤드폰(Telephonics, Farmingdale, NY, USA)을 사용하였다. 음장에서 보청기 착용 후 WRS 평가는 1분간 측정했을 때 $40 \mathrm{~dB} \mathrm{~L}_{\mathrm{Aeq}}$ 이하의 소음레 벨을 나타내는 방음실에서 음장 스피커(4 Ohms)를 이용하여 실 시하였고, 보청기의 이득 조절은 AURICAL FreeFit (GN Otometrics) 실이 측정기와 NAL-NL2 보청기적합공식을 사용하였 다. WRS의 측정은 한국산업표준 단음절어표(Korean standard monosyllabic word lists for adults) (KS I, 2018), 보청기 착용 효 과에 대한 평가 설문지는 K-IOI-HA를 사용하였다.

\section{연구 절차}

본 연구에서는 감각신경성 난청인의 선호이득인 PREIG-K 를 확인한 후 NAL-NL2의 REIG와 비교하고, PREIG-K의 신 뢰성을 확인하기 위하여 PREIG-K의 고주파수 대역을 NAL- 
Table 2. Gender, age, period of HA used, and hearing threshold levels of subjects for modified preferred real-ear insertion gain for Korean

\begin{tabular}{|c|c|c|c|c|c|c|c|c|c|c|c|}
\hline \multirow{2}{*}{ Subject } & \multirow{2}{*}{ Gender } & \multirow{2}{*}{$\begin{array}{c}\text { Age } \\
\text { (year) }\end{array}$} & \multirow{2}{*}{ HA site } & \multirow{2}{*}{$\begin{array}{c}\text { Period } \\
\text { (year) }\end{array}$} & \multicolumn{7}{|c|}{ Hearing threshold level (dB HL) in $\mathrm{kHz}$} \\
\hline & & & & & 0.125 & 0.25 & 0.5 & 1.0 & 2.0 & 4.0 & 8.0 \\
\hline \multirow[t]{2}{*}{ S1 } & M & 77 & $\mathrm{~L}$ & 1.3 & 55 & 60 & 75 & 95 & 80 & 70 & 120 \\
\hline & & & $\mathrm{R}$ & 1.3 & 15 & 15 & 25 & 50 & 65 & 80 & 90 \\
\hline \multirow[t]{2}{*}{$\mathrm{S} 2$} & M & 73 & $\mathrm{~L}$ & 6.2 & 25 & 30 & 40 & 50 & 65 & 75 & 100 \\
\hline & & & $\mathrm{R}$ & 6.2 & 25 & 30 & 45 & 55 & 60 & 90 & 95 \\
\hline \multirow[t]{2}{*}{ S3 } & $\mathrm{M}$ & 83 & $\mathrm{~L}$ & 2.2 & 55 & 55 & 55 & 65 & 70 & 85 & 90 \\
\hline & & & $\mathrm{R}$ & 2.2 & 45 & 45 & 40 & 60 & 70 & 75 & 70 \\
\hline \multirow[t]{2}{*}{ S4 } & $\mathrm{M}$ & 80 & $\mathrm{~L}$ & 0.9 & 50 & 55 & 65 & 75 & 85 & 100 & 95 \\
\hline & & & $\mathrm{R}$ & 0.9 & 50 & 50 & 55 & 65 & 55 & 80 & 90 \\
\hline \multirow[t]{2}{*}{ S5 } & $\mathrm{M}$ & 76 & $\mathrm{~L}$ & 1.9 & 30 & 35 & 40 & 45 & 45 & 75 & 65 \\
\hline & & & $\mathrm{R}$ & 1.9 & 5 & 10 & 20 & 35 & 40 & 65 & 70 \\
\hline \multirow[t]{2}{*}{ S6 } & $\mathrm{M}$ & 71 & $\mathrm{~L}$ & 1.9 & 25 & 30 & 55 & 55 & 50 & 65 & 60 \\
\hline & & & $\mathrm{R}$ & 1.9 & 20 & 25 & 45 & 50 & 50 & 65 & 75 \\
\hline
\end{tabular}

HA: hearing aid, M: male, L: left, R: right

$\mathrm{NL} 2$ 와 같게 조절한 후 조절 전과 후의 $\mathrm{WRS}$ 를 측정하였다.

\section{PREIG-K의 확인}

PREIG-K의 확인 방법은 첫째, 실이 측정기의 청력 데이터 입력 화면에 기도 및 골도 HTL을 입력하고, 보청기적합공식 NAL-NL2를 선택한 후 대상자의 성별, 나이, 보청기 착용 경 험 및 착용 귀 그리고 보청기의 형태를 입력하였다. 둘째, 실이 공명반응(real-ear unaided response)과 실이증폭반응(realear aided response)의 측정을 통해 나타난 입력 SPL 50, 65, $80 \mathrm{~dB}$ 에 대한 REIG를 NAL-NL2의 목표이득(target gain)과 최대한 일치하도록 조절하였다. 셋째, 대상자에게 국제어음시험 신호(international speech test signal)를 외부 스피커를 통하 여 50, 65, $80 \mathrm{~dB}$ SPL로 제시한 후, 대상자의 반응을 고려하여 전체 음량, 작은 소리, 보통 크기 및 큰 소리에 대한 이득, 그리 고 음질을 고려하여 저주파수 및 고주파수의 이득을 조절하였 다. 넷째, 보청기 착용 후 최소 6개월이 지났을 때 재방문하게 하여 K-IOI-HA 평가를 통해 더 이상 이득의 조절이 필요하지 않을 때 방음실에서 보청기 착용 후 $\mathrm{WRS}$ 를 측정하고, $1 / 2$ 옥 타브 주파수별로 입력 SPL 50, 65, $80 \mathrm{~dB}$ 에 대한 REIG를 확 인하였다. WRS의 평가는 방음실 내의 스피커에서 $1 \mathrm{~m}$ 떨어진 위치(0 degree azimuth)에 대상자를 앉히고, 단음절어를 육성 으로 제시하여 각각의 귀에서 측정하였다. 제시한 어음의 SPL 은 $45 \mathrm{~dB} \mathrm{HL}$ 이었으며, 단음절의 수는 25 개였다. 그리고 $\mathrm{K}-$ IOI-HA는 대상자가 설문지에 직접 작성하도록 하였다.

\section{PREIG-K와 $\mathrm{M}-\mathrm{PREIG}-\mathrm{K}$ 의 WRS 측정}

PREIG-K와 M-PREIG-K에 따른 WRS의 측정 방법은 첫째, PREIG-K의 확인 시 WRS를 측정하였다. 둘째, 난청인의 폐쇄 효과(occlusion effect)를 고려하여 저주파수 이득은 그대로 두 고, $1.5 \mathrm{kHz}$ 이상의 고주파수 대역에서 입력 SPL $50,65,80 \mathrm{~dB}$ 에 대한 이득을 NAL-NL2와 같게 조절하였다. 이때 PREIG-K 와 NAL-NL2의 연결 부분은 부드럽게 나타나도록 조절하였다. 셋째, 조절 직후, 즉 M-PREIG-K의 WRS를 측정하였으며 측정 은 PREIG-K에서 WRS를 측정한 방법과 동일하다.

\section{통계 분석}

각각의 $1 / 2$ 옥타브 주파수에서 그룹 내 독립변수인 적합공식 (PREIG-K, NAL-NL2)과 입력 SPL (50, 65, 80 dB SPL)이 REIG에 미치는 영향을 확인하기 위해 반복측정 이원분산분석 (2-way analysis of variance with repeated measures)을 시행 하였다. 그리고 입력 SPL과 적합공식 간 상호작용이 나타나는 경우 대응표본 $t$-검정(paired $t$-test)을 실시하여 3개의 입력 $\mathrm{SPL}$ 과 2개의 적합공식을 고려한 수정 $p$ 값 0.008 이하에서 확 인하였다. 아울러 입력 SPL과 PREIG-K에서 HTL에 따른 REIG의 변화를 확인하기 위해 회귀 분석을 실시하였다. PRE$\mathrm{IG}-\mathrm{K}$ 와 M-PREIG-K에 따른 WRS의 차이는 대응표본 $t$-검정 을 통하여 유의수준 0.05 이하에서 확인하였다. 통계 분석은 SPSS 25.0(IBM Corp., Armonk, NY, USA)을 사용하였다.

\section{RESULTS}

\section{PREIG-K와 NAL-NL2의 이득}

Figure 3 의 입력 SPL $50,65,80 \mathrm{~dB}$ 에 따른 평균 REIG에서 NAL-NL2는 $0.25 \mathrm{kHz}$ 에서 $8.0 \mathrm{kHz}$ 까지 점차 증가하는 것으로 나타났으나, PREIG-K는 $0.25 \mathrm{kHz}$ 에서 $1.5 \mathrm{kHz}$ 까지는 NAL$\mathrm{NL} 2$ 에 비해 급격하게 증가하였다가 $2.0 \mathrm{kHz}$ 이상에서는 주파 


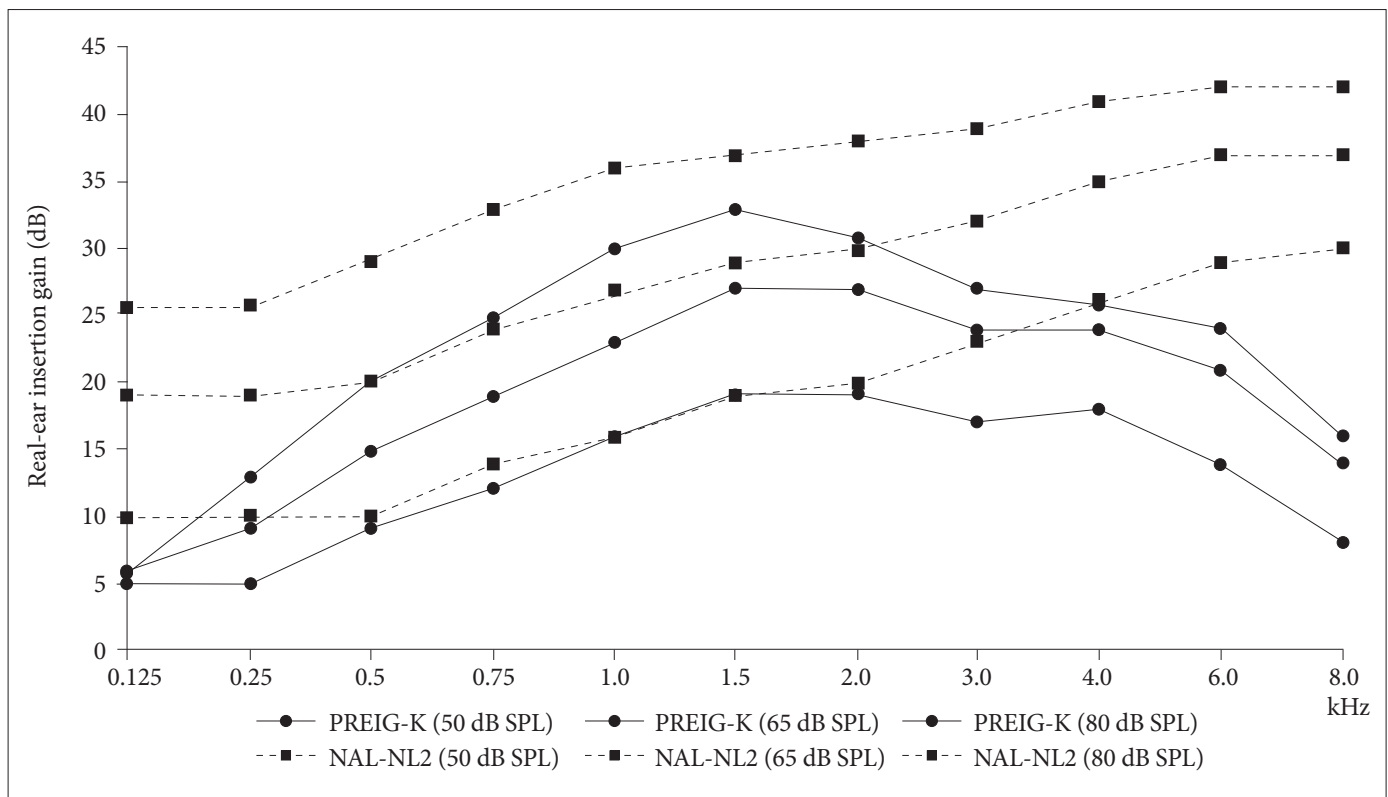

Figure 3. Real-ear insertion gain of PREIG-K and NAL-NL2 (National Acoustic Laboratories) as a function of input SPL 50, 65 , and $80 \mathrm{~dB}$ SPL at each 1/2 octave frequencies. PREIG-K: preferred real-ear insertion gain for Korean, NAL-NL2: National Acoustics Laboratories-NonLinear version 2, SPL: sound pressure level.

수가 증가할수록 REIG가 점차 감소하는 것으로 나타났다.

반복측정 이원분산분석 결과 모든 $1 / 2$ 옥타브 주파수에서 적합공식(PREIG-K, NAL-NL2) 그리고 입력 SPL(50, 65, 80 $\mathrm{dB})$ 에 따른 REIG의 차이가 나타났다 $(p<0.01)$. 그리고 모든 $1 / 2$ 옥타브 주파수에서 적합공식과 입력 SPL 간에 상호작용이 나타났는데 $(p<0.01)$, PREIG-K는 NAL-NL2에 비해 REIG 가 낮게 나타났다. Table 3에 적합공식(PREIG-K, NAL-NL2) 의 입력 SPL에 따른 반복측정 이원분산분석의 결과를 나타내 었다.

\section{입력음압레벨에 따른 PREIG-K와 NAL-NL2의 차이}

$1 / 2$ 옥타브 주파수에서 입력 SPL에 따른 적합공식 PREIG-K 와 NAL-NL2에 의한 REIG의 차이를 살펴보면 $50 \mathrm{~dB}$ SPL에서 는 모든 주파수, $65 \mathrm{~dB} \mathrm{SPL}$ 에서는 $1.5 \mathrm{kHz}\left[t_{(61)}=-2.504, p\right.$ > 0.008 를 제외한 모든 주파수에서 차이가 나타났다. 그리고 $80 \mathrm{~dB}$ SPL에서는 $0.5 \mathrm{kHz}\left[t_{(61)}=-0.535, p>0.008\right], 0.75 \mathrm{kHz}\left[t_{(61)}=\right.$ $-2.602, p>0.008], 1.0 \mathrm{kHz}\left[t_{(61)}=-0.372, p>0.008\right], 2.0$ $\mathrm{kHz}\left[t_{(61)}=-1.133, p>0.008\right]$ 를 제외한 주파수에서 차이가 나 타났다.

\section{PREIG-K의 HTL에 따른 REIG의 기울기}

보통 대화음레벨 $65 \mathrm{~dB}$ SPL에서 HTL에 따른 REIG에 대해 어음의 인지와 관련성이 높은 $0.5,1.0,2.0,4.0 \mathrm{kHz}$ 의 주파수에 서 회귀 분석을 실시하였다. 분석 결과 Figure 4 에서 $0.5,1.0$, $2.0,4.0 \mathrm{kHz}$ 의 조정(adjusted) $\mathrm{r}^{2}$ 값은 $0.475(p<0.001), 0.585(p<$
0.001), 0.443( $p<0.001), 0.373(p<0.001)$, 기울기는 0.392, 0.507, $0.437,0.339$ 로 각각 나타났다.

\section{PREIG-K와 M-PREIG-K의 WRS}

PREIG-K와 M-PREIG-K의 평균 WRS는 각각 $62.0 \%$ 와 $66.0 \%$ 로 고주파수 대역의 이득을 조절하기 전과 후에 의미 있 는 차이는 나타나지 않았다 $\left[t_{(11)}=-0.804, p>0.05\right]$ (Figure 5).

\section{DISCUSSIONS}

\section{PREIG-K와 NAL-NL2}

한국 감각신경성 난청인의 선호이득 PREIG-K에서 입력 SPL에 대한 REIG는 $1.5 \mathrm{kHz}$ 에서 가장 높게 나타났으며, 모든 $1 / 2$ 옥타브 주파수에서 NAL-NL2의 목표이득에 비해 낮게 나 타났다. 특히 $0.75 \mathrm{kHz}$ 이하 그리고 $3.0 \mathrm{kHz}$ 이상의 주파수에 서 NAL-NL2에 비해 더 낮게 나타났다. Jin et al.(2017)의 연 구에서는 60 80세의 중도 이상의 난청인을 대상으로 보청기원 형을 이용하여 한국어의 음향적 특성을 고려한 보청기적합공 식의 효용성을 확인하였는데, 한국 감각신경성 난청인의 REIG 는 $0.5 \mathrm{kHz}$ 이하와 $4.0 \mathrm{kHz}$ 이상의 주파수 대역에서 NALNL2와 DSL 5.0에 비해서 낮게 나타나 본 연구와 비슷하였다. 그러나 $1.0 \mathrm{kHz}$ 와 $2.0 \mathrm{kHz}$ 에서 $60 \mathrm{~dB}$ SPL과 $80 \mathrm{~dB}$ SPL에 대 한 REIG는 NAL-NL2에 비해서 높게 나타나 본 연구와 차이 를 나타냈다. 하지만 Jin et al.(2017)의 연구에서 사용한 보청기 적합공식 NAL-NL2는 Eleva 411(Phonak, Stäfa, Switzer- 
land), DSL 5.0은 Savia 311(Phonak) 보청기에 적용한 보청기 적합 소프트웨어에서 나타나는 REIG를 그대로 사용했기 때문 에 본 연구와의 비교는 어려움이 있었다.

$0.25 \mathrm{kHz}$ 에서 $1.5 \mathrm{kHz}$ 까지 입력 SPL $50 \mathrm{~dB}$ 과 $65 \mathrm{~dB}$ 에 대한 이득곡선의 기울기는 PREIG-K가 NAL-NL2에 비해 더 가파 르게 상승하는 것으로 나타났다. Byrne et al.(1994), IEC(2012) 에서 각국 언어의 장기평균어음스펙트럼은 서로 다르게 나타난 다고 보고하였다. 그리고 Lee et al.(2008), Noh \& Lee(2012)의 연구에서 한국어의 장기평균어음스펙트럼은 영어에 비해 저주 파수와 고주파수의 에너지 차이가 더 크게 나타나며, $0.25 \mathrm{kHz}$ 에서 $1.5 \mathrm{kHz}$ 까지의 에너지 감소가 더 급격하게 일어난다고 보 고하였다. 일반적으로 이득은 보통 크기의 대화음레벨을 난청인 의 $\mathrm{MCL}$ 부근으로 증폭하기 위해 필요한 양으로 결정하는데, 한 국어의 장기평균어음스펙트럼이 고주파수로 향할수록 급격하게 감소하기 때문에 이득은 급격하게 상승한 것으로 보인다. 또한 저주파수 대역의 이득이 높을 경우 폐쇄 효과에 의한 소리의 울 림(Dillon, 2012; Park \& Lee, 2019), 상향 차폐(Yasin \& Plack, 2005) 등에 영향을 받을 수 있는데 PREIG-K에서 저주파수 대 역의 기울기는 이러한 요소에 영향을 받은 것으로 볼 수 있다.

PREIG-K는 $1.5 \mathrm{kHz}$ 에서 가장 높은 이득이 나타났으며, 그 이상의 주파수 대역에서는 REIG가 점차 낮아지는 것으로 나 타나 NAL-NL2와 차이를 나타냈다. 그 이유는 NAL-NL2는 음질을 포함하여 어음명료도를 고려하였기 때문에 고주파수 대역의 이득을 강조하는 형태로 나타난다고 하였다(Byrne \& Dillon, 1986; Byrne et al., 2001; Keidser et al., 2011). 그러나 본 연구의 PREIG-K는 보청기 착용 시 음량, 음질 등 선호도 만을 고려하였기 때문에 차이가 나타난 것으로 보인다. 그럼에 도 불구하고 난청인의 K-IOI-HA 설문이 30점 이상의 점수가 나타난 것은 Lee \& Kim(2012), Jin et al.(2015)이 보고하였듯 이 한국 단음절어 및 문장의 대역중요함수가 영어에 비해 1.25 $\mathrm{kHz}$ 이하의 저주파수 대역에서 높게 나타나기 때문일 것으로 생각한다.

근래에 들어 보청기 제조사는 자사가 개발한 보청기적합공 식을 소프트웨어에 탑재하여 보청기의 조절에 사용하고 있다. 본 연구에 참여한 대상자의 평균 HTL을 Oticon, Phonak, Wi$\mathrm{dex}$ 사의 보청기적합 소프트웨어에 입력하고 각 회사의 보청기 적합공식인 $\mathrm{VAC}+, \mathrm{APD}, \mathrm{WIDEX}$ 를 선택하여, $1 / 2$ 옥타브 주파 수별로 입력 SPL $65 \mathrm{~dB}$ 에 대한 REIG를 살펴보았다. Figure 6 에서 PREIG-K는 $0.125 \mathrm{kHz}$ 에서 $1.5 \mathrm{kHz}$ 까지 보청기 제조사 의 적합공식과 비슷한 기울기를 나타냈으나, $1.5 \mathrm{kHz}$ 이상에서 는 PREIG-K의 이득이 감소하여 이득의 차이가 점차 커지는 형태로 나타났다. 특히 $1.5 \mathrm{kHz}$ 이하의 이득곡선은 Oticon의 $\mathrm{VAC}+$ 와 비슷하게 나타났다. 각 보청기 제조사에서 개발한 보
Table 3. The results of 2-way analysis of variance with repeated measures for real-ear insertion gain of fitting formula and input SPL

\begin{tabular}{lcrrr}
\hline Frequency & Analysis & \multicolumn{1}{c}{$\mathrm{F}$} & \multicolumn{1}{c}{ df, error } & $p$-value \\
\hline $0.125 \mathrm{kHz}$ & Main effects & & & \\
& Fitting formula & 112.937 & $1,61.000$ & $<0.001$ \\
& Input SPL & 174.426 & $1.307,79.734$ & $<0.001$ \\
& Interaction & 195.773 & $1.405,85.714$ & $<0.001$ \\
$0.25 \mathrm{kHz}$ & Main effects & & & \\
& Fitting formula & 102.255 & $1,61.000$ & $<0.001$ \\
& Input SPL & 202.686 & $1.135,69.214$ & $<0.001$ \\
& Interaction & 100.974 & $1.338,81.602$ & $<0.001$ \\
$0.5 \mathrm{kHz}$ & Main effects & & & \\
& Fitting formula & 28.552 & $1,61.000$ & $<0.001$ \\
& Input SPL & 264.936 & $1.102,67.217$ & $<0.001$ \\
& Interaction & 64.164 & $1.247,76.041$ & $<0.001$
\end{tabular}

$0.75 \mathrm{kHz} \quad$ Main effects

Fitting formula $\quad 41.027 \quad 1,61.000<0.001$

Input SPL $\quad 824.974 \quad 1.107,67.553<0.001$

Interaction $\quad 103.9541 .320,80.496<0.001$

$1.0 \mathrm{kHz} \quad$ Main effects

Fitting formula $\quad 18.647 \quad 1,61.000<0.001$

Input SPL $\quad 1,982.504 \quad 1.179,71.923<0.001$

Interaction $\quad 77.857 \quad 1.472,89.812<0.001$

$1.5 \mathrm{kHz} \quad$ Main effects

Fitting formula $\quad 7.645 \quad 1,61.000 \quad 0.008$

Input SPL $\quad 2,197.998 \quad 1.250,76.243<0.001$

Interaction $\quad 56.467 \quad 1.465,89.358<0.001$

$2.0 \mathrm{kHz} \quad$ Main effects

Fitting formula $\quad 20.551 \quad 1,61.000<0.001$

Input SPL $\quad 2,237.947 \quad 1.291,78.740<0.001$

Interaction $\quad 78.614 \quad 1.488,90.795<0.001$

$3.0 \mathrm{kHz}$

Main effects

Fitting formula $\quad 108.369 \quad 1,61.000<0.001$

Input SPL $\quad 1,487.0841 .352,82.468<0.001$

Interaction $\quad 103.3551 .381,84.229<0.001$

$4.0 \mathrm{kHz} \quad$ Main effects

Fitting formula $158.168 \quad 1,61.000<0.001$

Input SPL $\quad 1,657.437 \quad 1.441,87.886<0.001$

Interaction $\quad 146.074 \quad 1.462,89.209<0.001$

$6.0 \mathrm{kHz} \quad$ Main effects

Fitting formula $163.500 \quad 1,61.000<0.001$

Input SPL $\quad 1,121.671 \quad 1.441,87.910<0.001$

Interaction $\quad 44.5101 .563,95.352<0.001$

$8.0 \mathrm{kHz} \quad$ Main effects

Fitting formula $297.419 \quad 1,61.000<0.001$

Input SPL $\quad 381.3731 .579,96.290<0.001$

Interaction $\quad 9.538 \quad 1.689,103.041 \quad 0.003$

SPL: sound pressure level 

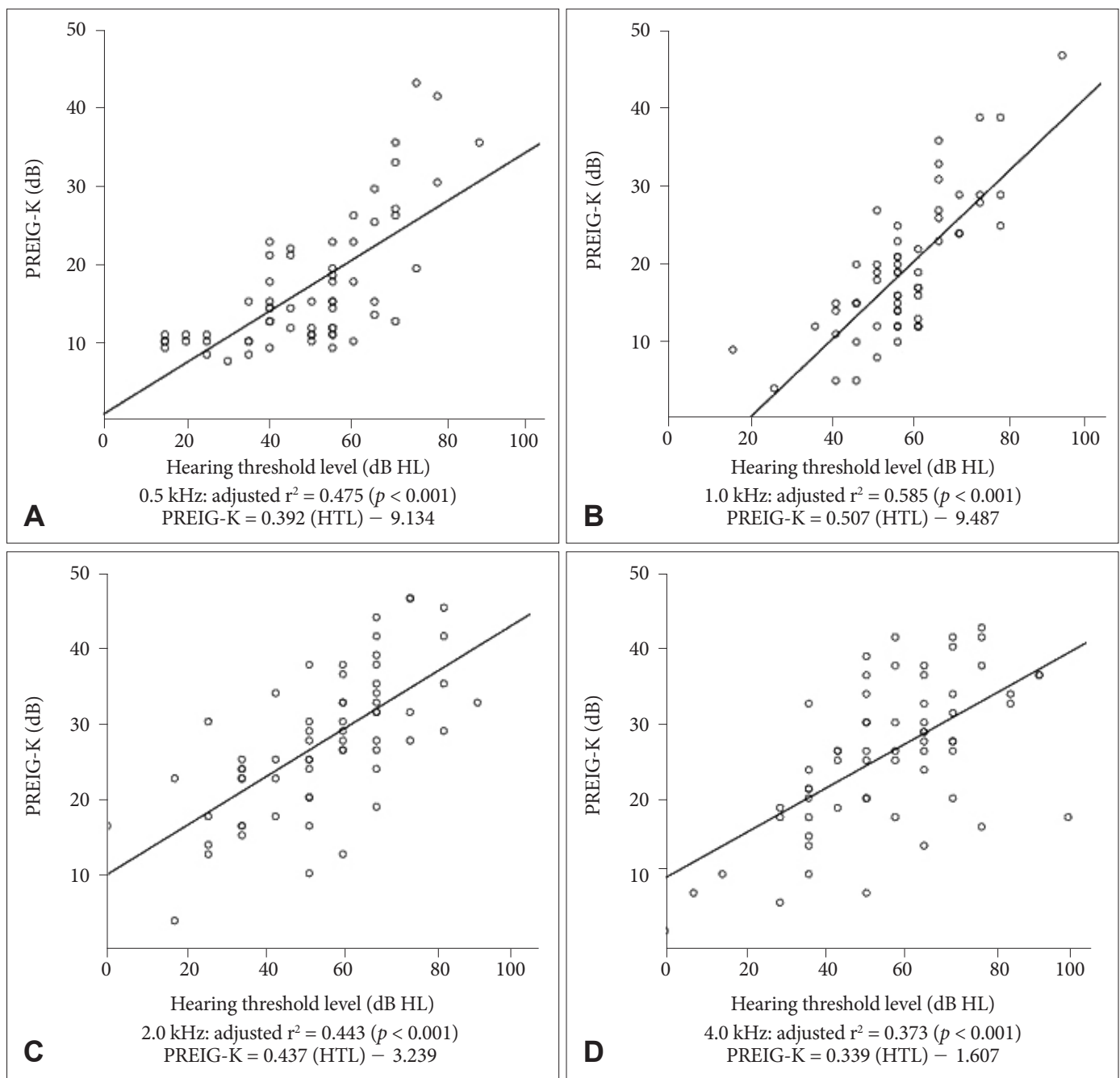

Figure 4. Changes of PREIG for Korean for $65 \mathrm{~dB}$ SPL input as a function of hearing threshold levels at $0.5(\mathrm{~A}), 1.0$ (B), 2.0 (C), and 4.0 (D) kHz. PREIG-K: preferred real-ear insertion gain for Korean, HTL: hearing threshold level.

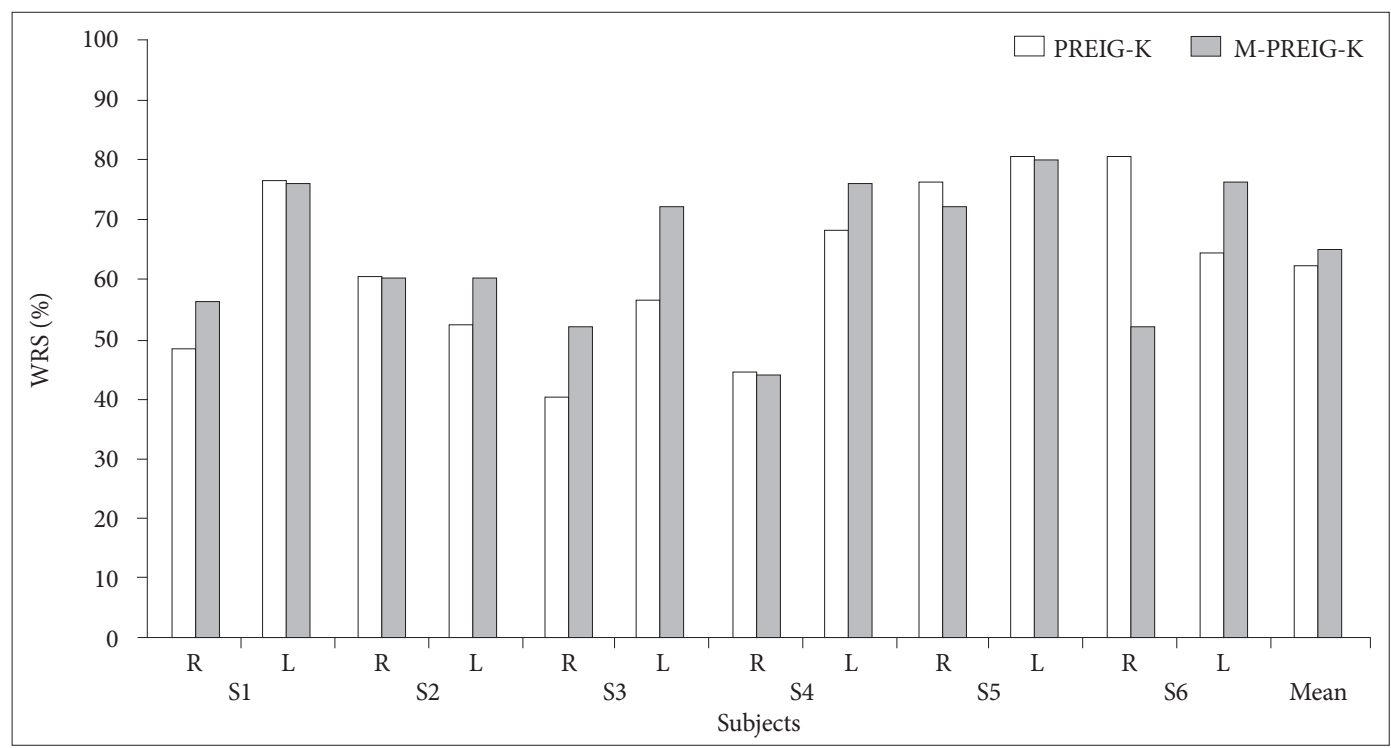

Figure 5. WRSs of PREIG-K and M-PREIG-K. WRS: word recognition score, PREIG-K: preferred real-ear insertion gain for Korean, MPREIG-K: modified PREIG-K. 


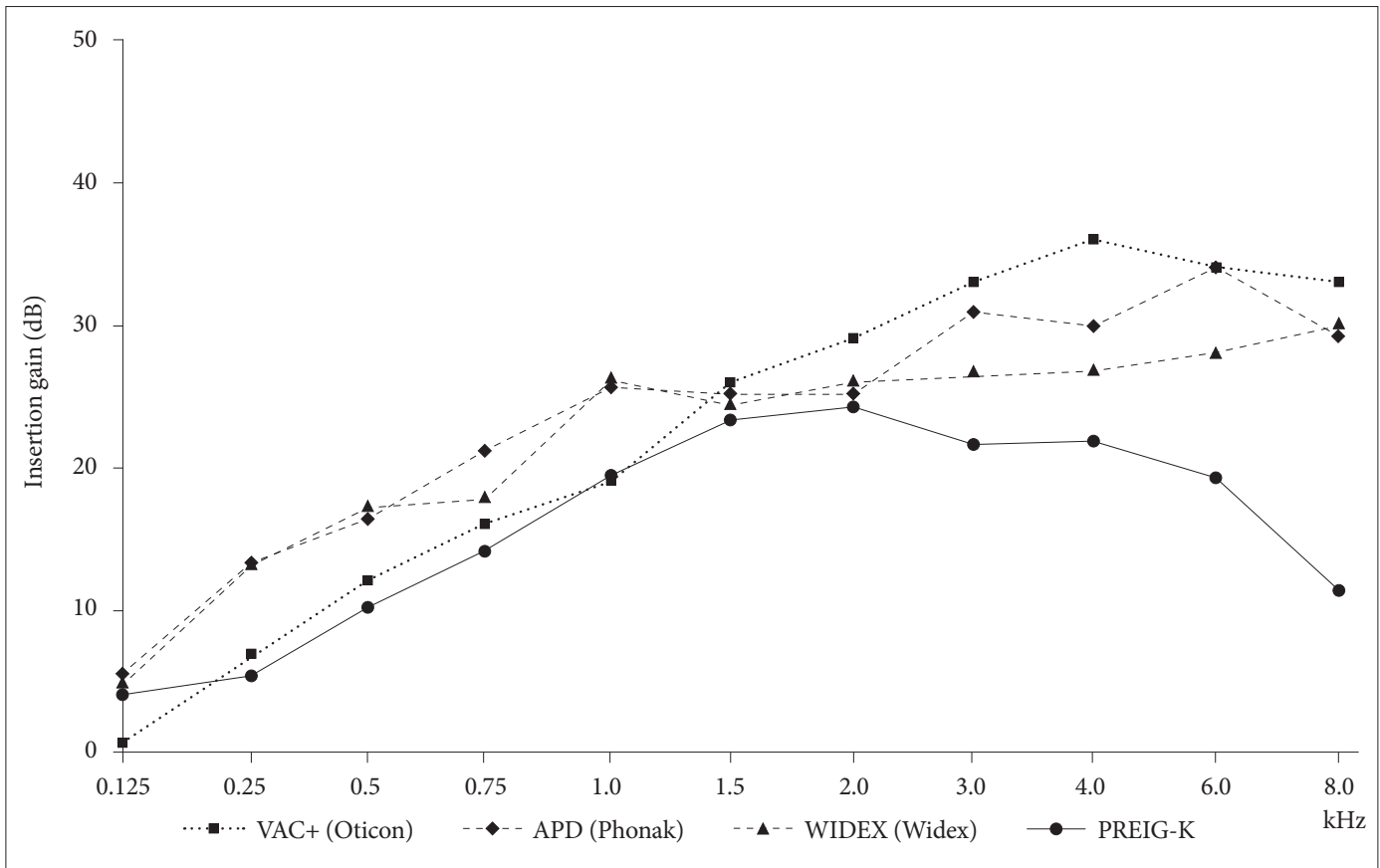

Figure 6. Insertion gain for $65 \mathrm{~dB}$ input sound pressure level of PREIG and when the mean hearing threshold level of subjects in this study were entered into the manufacturers' fitting formula VAC+ (Oticon), APD (Phonak), WIDEX (Widex). PREIG: preferred real-ear insertion gain, PREIG-K: PREIG for Korean.

청기적합공식은 실제 보청기적합 시 발생하는 폐쇄 효과 또는 상향 차폐를 줄이기 위한 것으로 생각할 수 있다. 그리고 본 연구 에서는 $1.5 \mathrm{kHz}$ 부근의 이득이 최대로 나타나 Aarts \& Caffee (2005)가 보고한 제조사의 보청기적합공식의 이득과 비슷한 결 과를 나타냈다.

입력 SPL $80 \mathrm{~dB}$ 에서 REIG는 $0.5 \mathrm{kHz}$ 에서 $2.0 \mathrm{kHz}$ 까지 PREIG-K와 NAL-NL2 간에는 차이가 나타나지 않았다. 건청 인의 $0.5 \mathrm{kHz}$ 와 $3.0 \mathrm{kHz}$ 의 불쾌음량레벨 연구에서 Park \& Lee(2013)는 88.5 dB HL과 88.7 dB HL, Shin et al.(2008)은 $97.9 \mathrm{~dB}$ HL과 $91.2 \mathrm{~dB}$ HL로 보고하였으며, Cox et al.(1997) 은 $97.1 \mathrm{~dB}$ HL과 $94.7 \mathrm{~dB}$ HL, Beattie et al.(1997)은 $92.4 \mathrm{~dB}$ $\mathrm{HL}$ 과 $87.0 \mathrm{~dB} \mathrm{HL}$ 로 보고하였다. 이 결과를 비추어 볼 때 한 국인과 영어권 사람들의 HTL에 따른 불쾌음량레벨의 차이가 크지 않아서 $80 \mathrm{~dB}$ SPL에 대한 이득 또한 비슷하게 나타났다 고 볼 수 있다. 그리고 $2.0 \mathrm{kHz}$ 이상의 주파수에서 PREIG-K 가 NAL-NL2에 비해 감소한 이유는 날카로운 음의 조절 과정 에서 입력 SPL 전체 이득을 조절하여 발생한 것이라고 생각할 수 있다.

본 연구에서 PREIG-K의 압축역치는 모든 $1 / 2$ 옥타브 주파 수에서 $50 \mathrm{~dB}$ SPL로 유추할 수 있어서 NAL-NL2와 비슷하 게 나타났다. Barker \& Dillon(1999)은 경도에서 중도의 감각 신경성 난청인은 압축비율이 2:1인 단채널 보청기에서 $65 \mathrm{~dB}$ SPL의 압축역치를 선호한다고 하였다. 한국의 연구에서 Kim
\& Lee(2019)는 55, 65, $75 \mathrm{~dB}$ SPL의 압축역치에 따른 초성자 음 인지도를 비교하였는데 백색잡음하에서는 $75 \mathrm{~dB}$ SPL에 비 해 $55 \mathrm{~dB}$ SPL과 $65 \mathrm{~dB}$ SPL의 압축역치에서 더 높은 WRS를 나타냈으나, 선호도에서는 $55 \mathrm{~dB} \mathrm{SPL}$ 의 압축역치에서 잡음의 크기가 더 크다고 보고하였다. 그리고 Han et al.(2017)은 압축 역치를 $31 \mathrm{~dB}$ SPL과 $61 \mathrm{~dB}$ SPL로 구분하여 어음인지역치 (word recognition threshold), 소리의 크기, 날카로움, 명료성, 주변 잡음에 대해서 알아보았는데 의미 있는 차이는 나타나지 않았다. 그러나 본 연구에서 한국 감각신경성 난청인이 선호하 는 이득은 압축역치에 따른 어음인지도보다는 단순히 음질의 선호도를 확인한 것이어서 상기 한국의 선행연구와 부분적인 일치성은 나타나지만 구체적인 비교에는 어려움이 있다.

그리고 본 PREIG-K의 압축비율은 $0.125 \mathrm{kHz}$ 와 $0.25 \mathrm{kHz}$ 에서 1.01:1과 1.19:1로 가장 낮게 나타났으며, $1.0 \mathrm{kHz}$ 와 1.5 $\mathrm{kHz}$ 에서 1.77:1과 $1.84: 1$ 로 가장 높게 나타난 것으로 유추할 수 있다. 이 결과는 모든 주파수에서 NAL-NL2의 압축비율에 비 해 낮게 나타났다. Park \& Lee(2015)는 경중도의 감각신경성 난청인을 대상으로 $6 \mathrm{~dB}, 0 \mathrm{~dB}$ 의 신호대잡음비의 백색잡음하 에서 압축비율에 따른 문장인지도를 알아보았는데 2:1의 압축 비율에서 인지도와 선호도가 가장 높게 나타났으나 의미 있는 차이는 아니었다. 그리고 Shin \& Lee(2017)는 보청기 착용 경 험이 있는 중도 전후의 감각신경성 난청인을 대상으로 해제시 간이 46 85 ms인 다채널보청기의 압축 방식을 저대역압축, 고대 
역압축, 다채널압축으로 구분하여 조용한 곳 그리고 $6 \mathrm{~dB}, 0 \mathrm{~dB}$ 의 백색잡음 신호대잡음비에서 문장인지도와 명료성, 배경소 음, 전체적인 선호도를 알아보았는데 다채널압축 방식이 문장 인지도와 명료성이 더 높고 명료한 것으로 나타났다. 결과적으 로 본 연구의 압축비율 또한 압축역치와 마찬가지로 어음인지 도보다는 단순히 음질의 선호도를 확인한 것이어서 상기 한국 의 선행연구와 부분적인 일치성은 나타나지만 구체적인 비교에 는 어려움이 있다.

$65 \mathrm{~dB}$ SPL에서 HTL에 따른 PREIG-K에 대해 회기 분석을 실시했을 때 $0.5,1.0,2.0,4.0 \mathrm{kHz}$ 에서 PREIG-K의 기울기는 0.392(조정 $r^{2}=0.475$ ), 0.507(조정 $r^{2}=0.585$ ), 0.437(조정 $r^{2}=$ 0.443), 0.339(조정 $r^{2}=0.373$ )로 나타났다. Park \& Lee(2013)의 연구에서 $45 \mathrm{~dB}$ HL에서 $75 \mathrm{~dB}$ HL의 HTL에 따른 MCL과 $\mathrm{UCL}$ 을 $30 \mathrm{~dB} \mathrm{HL}$ 에서 $75 \mathrm{~dB}$ HL까지로 확대하여 재분석했을 때 $0.5 \mathrm{kHz}$ 와 $3.0 \mathrm{kHz}$ 의 기울기는 MCL이 0.552 와 0.537 , UCL 은 0.192 와 0.274 로 나타났다. 이를 본 연구의 HTL에 따른 $\mathrm{REIG}$ 의 기울기와 비교하면 MCL의 경우 $1.0 \mathrm{kHz}$ 는 비슷하게 나타났으나, $0.5,2,4 \mathrm{kHz}$ 의 기울기는 본 연구가 낮게 나타났다. 그리고 UCL의 경우 $0.5 \mathrm{kHz}$ 는 비슷하게 나타났으나 $1.0 \mathrm{kHz}$ 이상의 주파수에서는 본 연구가 높게 나타난 것으로 추측할 수 있다. Byrne \& Dillon(1986)의 보청기적합공식 연구에서 이득 을 HTL의 0.46 배로 설정하여 본 연구와 차이를 나타냈다. 이 는 본 연구에서 다채널 보청기의 이득 조절 시 어음인지도보다 는 음질 등 대상자의 주관적인 판단에 의존했기 때문이라고 생 각한다.

\section{PREIG-K와 M-PREIG-K의 WRS}

PREIG-K와 고주파수 대역의 이득을 NAL-NL2와 같게 조 절한 $\mathrm{M}-\mathrm{PREIG}-\mathrm{K}$ 의 WRS가 방음실에서 차이가 나타나는지 를 확인하였는데, 조절 전과 후의 WRS는 $62.0 \%$ 와 $66.0 \%$ 로 유의미한 차이는 나타나지 않았다. 본 연구의 결과에서 PRE$\mathrm{IG}-\mathrm{K}$ 는 $2.0 \mathrm{kHz}$ 이상의 주파수에서 REIG가 감소하여 NAL$\mathrm{NL} 2$ 와 차이가 나타났다. 그럼에도 불구하고 PREIG-K의 WRS가 M-PREIG-K와 차이가 나타나지 않은 것은 Lee \& Kim(2012), Jin et al.(2015)이 보고하였듯이 한국어 대역중요 함수가 $2.0 \mathrm{kHz}$ 이상에서 낮게 나타나며, 한국어의 경우 자음 의 사용 빈도가 영어에 비해 적기 때문으로 볼 수 있다. 그러나 PREIG-K와 M-PREIG-K의 비교는 조용한 환경에서 WRS 로 평가하였는데 난청인에게 효과적인 이득의 비교를 위해서는 조용한 환경에서의 WRS 외에도 다양한 잡음을 고려하여야 하며, 음질 등 난청인의 실생활을 고려한 환경에서 다양한 평가 가 이루어져야 할 것이다.

본 연구에서 REIG는 $0.25 \mathrm{kHz}$ 에서 $1.5 \mathrm{kHz}$ 까지 한국 난청
인의 선호이득이 NAL-NL2에 비해 낮게 나타났으며, $50 \mathrm{~dB}$ SPL과 $65 \mathrm{~dB}$ SPL에 대한 이득곡선의 기울기가 가파르게 상승 한 이유에 대해서 장기평균어음스펙트럼과 대역중요함수를 주 요 요인으로 설명하였다. 하지만 한국어의 경우 이 두 가지 요 인은 이득을 산출함에 있어서 서로 상반적인 특징을 가지고 있 어서 향후 추가적인 연구가 필요할 것으로 생각한다. 그리고 본 연구 대상자의 평균 연령이 76.8세(범위: 61 89세, 표준편차: 7.37)로 높은 편이며, 개방적합형, 귓속형 등 보청기의 형태별 PREIG-K를 확인하지 않은 것은 본 연구의 한계점으로 볼 수 있다. 향후 한국 감각신경성 난청인에게 필요한 이득을 효과적 으로 산출하기 위해서는 한국인이 발성하는 대화음레벨, 장기 평균어음스펙트럼, 어음역동범위, 어음명료지수 등 어음의 특 성, 실이공명반응, 실이대커플러차, 실이대다이얼차 등 한국인 의 신체적인 특징, 보청기의 착용 기간, 보청기의 형태, 단측 또 는 양쪽 등 착용 조건, 그리고 음향피드백, 압축역치와 압축비 율, 압축시간과 해제시간 등 보청기의 전기음향적 특성을 고려 한 연구가 필요할 것이다.

중심 단어 : 보청기적합공식·다채널 보청기·선호이득. 실이삽입이득·감각신경성난청.

\section{Ethical Statement}

This study was approved by the Institutional Review Board of Hallym University of Graduate Studies (IRB \# HUGSAUD 142830).

\section{Acknowledgments}

The authors thank to National Research Foundation of Korea.

\section{Declaration of Conflicting Interests}

There are no conflict of interests.

\section{Funding}

This research was completed while being supported by National Research Foundation of Korea (2018R1A2B6001986).

\section{Author Contributions}

K. L. designed experimental procedures. E. B. collected and analyzed data. E. B. and K. L. wrote the paper. E. B. and K. L. discussed the results together and implications at each data.

\section{ORCID iDs}

Eojini Bang https://orcid.org/0000-0002-5019-9770

Kyoungwon Lee https://orcid.org/0000-0002-1297-6436

\section{REFERENCES}

Aarts, N. L. \& Caffee, C. S. (2005). The accuracy and clinical usefulness of manufacturer-predicted REAR values in adult hearing aid fittings. The Hearing Review, 12(12), 16-22.

Barker, C. \& Dillon, H. (1999). Client preferences for compression threshold in single-channel wide dynamic range compression hearing aids. Ear and Hearing, 20(2), 127-139.

Beattie, R. C., Huynh, R. C., Ngo, V. N., \& Jones, R. L. (1997). IHAFF loudness contour test: Reliability and effects of approach mode in 
normal-hearing subjects. Journal of the American Academy of Audiology, 8(4), 243-256.

Blamey, P. J. \& Martin, L. F. A. (2009). Loudness and satisfaction ratings for hearing aid users. American Academy of Audiology, 20(4), 272282.

Byrne, D. \& Dillon, H. (1986). The National Acoustics Laboratories' (NAL) new procedure for selecting the gain and frequency response of a hearing aid. Ear and Hearing, 7(4), 257-265.

Byrne, D., Dillon, H., Ching, T., Katsch, R., \& Keidser, G. (2001). NALNL1 procedure for fitting nonlinear hearing aids: Characteristics and comparisons with other procedures. Journal of the American Academy of Audiology, 12(1), 37-51.

Byrne, D., Dillon, H., Tran, K., Arlinger, S., Wilbraham, K., Cox, R., et al. (1994). An international comparison of long-term average speech spectra. The Journal of the Acoustical Society of America, 96(4), 21082120.

Chu, H., Cho, Y. S., Park, S. N., Byun, J.. Y., Shin, J. E., Han, G. C., et al. (2012). Standardization for a Korean adaptation of the international outcome inventory for hearing aids: Study of validity and reliability. Korean Journal of Otorhinolaryngology-Head and Neck Surgery, 55(1), 20-25.

Cornelisse, L. E., Seewald, R. C., \& Jamieson, D. G. (1995). The input/output formula: A theoretical approach to the fitting of personal amplification devices. The Journal of the Acoustical Society of America, 97(3), 1854-1864.

Cox, R. M. (1995). Using loudness data for hearing aid selection: The IHAFF approach. The Hearing Journal, 48(2), 10, 39-44.

Cox, R. M., Alexander, G. C., Taylor, I. M., \& Gray, G. A. (1997). The contour test of loudness perception. Ear and Hearing, 18(5), 388-400.

Dillon, H. (1999). NAL-NL1: A new procedure for fitting non-linear hearing aids. The Hearing Journal, 52(4), 10, 12, 14, 16.

Dillon, H. (2012). Hearing Aids. (2nd ed.). Turramurra: Boomerang Press.

Eisenberg, L. S., Dirks, D. D., Takayanagi, S., \& Martinez, A. S. (1998). Subjective judgements of clarity and intelligibility for filtered stimuli with equivalent speech intelligibility index predictions. Journal of Speech, Language, and Hearing Research, 41(2), 327-339.

Han, W., Lee, J., Kim, J., Lee, K., \& Kim, D. (2017). Preferred compression threshold and release time in quiet and noisy conditions for elderly Korean hearing aid users. Journal of Audiology and Otology, 21(3), 133-139.

IEC. (2012). Electroacoustics-Hearing Aids-Part 15: Methods for Characterising Signal Processing in Hearing Aids with a Speech-Like Signal. Geneva: International Electrotechnical Commission.

Jenstad, L. M., Seewald, R. C., Cornelisse, L. E., \& Shantz, J. (1999). Comparison of linear gain and wide dynamic range compression hearing aid circuits: Aided speech perception measures. Ear and Hearing, 20(2), $117-126$.

Jeong, J. \& Lee, K. (2018). Changes of non-sense syllabic word scores and preferences as a function of release time on multi-channel hearing aids. Audiology and Speech Research, 14(4), 250-258.

Jin, I. K., Kates, J. M., Lee, K., \& Arehart, K. H. (2015). Derivations of the band-importance function: A cross-procedure comparison. The Journal of the Acoustical Society of America, 138(2), 938-941.

Jin, I. K., Lee, K., Kim, J., Kim, D, Sohn, J., \& Lee, J. (2017). Comparison of a hearing aid fitting formula based on Korean acoustic characteristics and existing fitting formulae. Audiology and Speech Research, 13(3), 216-221.
Keidser, G., Dillon, H., Flax, M., Ching, T., \& Brewer, S. (2011). The NALNL2 prescription procedure. Audiology Research, 1(1), 88-90.

Killion, M. C. \& Fikret-Pasa, S. (1993). The 3 types of sensorineural hearing loss: Loudness and intelligibility considerations. The Hearing Journal, 46(11), 31-36.

Kim, S. \& Lee, K. (2019). Changes of consonant recognition and sound quality as a function of compression threshold on multi-channel hearing aids. Audiology and Speech Research, 15(1), 23-29.

KS I. (2018). Acoustics-Hearing Aid Fitting Management. Seoul: Korean Standard Association.

Lee, K. W. (2014). Changes of dynamic range, signal-to-noise ratio, and consonant-to-vowel ratio by electroacoustic adjustment and fitting in non-linear hearing aids. Audiology, 10(3), 190-197.

Lee, K. W. \& Kim, J. S. (2011). Suggestion of hearing aid gain for Korean hearing impaired (HAG-K). Audiology, 7(2), 119-123.

Lee, K. W. \& Kim, J. S. (2012). The study of frequency importance function of the Korean monosyllabic words. Audiology, 8(1), 24-33.

Lee, K. W., Lee, J. H., \& Lee, J. (2008). Suggestions of multi-talker babble noise using Korean speech sound. Audiology, 4(1), 24-27.

Noh, H. \& Lee, D. H. (2012). Cross-language identification of long-term average speech spectra in Korean and English: Toward a better understanding of the quantitative difference between two languages. Ear and Hearing, 33(3), 441-443.

Park, J. \& Lee, K. (2019). Comparison of occlusion effect between ear-tip type of receiver-in-canal hearing aids and completely- in-the-canal. $\mathrm{Au}$ diology and Speech Research, 15(2), 95-100.

Park, S. Y. \& Lee, K. (2015). Comparisons of the sentence recognition scores and sound qualities as a function of compression ratios. Audiology, 11(4), 292-301.

Park, Y. J. \& Lee, K. W. (2013). A changes of loudness growth as a function of hearing threshold level in adults with normal and sensorineural hearing loss. Audiology, 9(1), 25-32.

Scollie, S., Seewald, R., Cornelisse, L., Moodie, S., Bagatto, M., Laurnagaray, D., et al. (2005). The desired sensation level multistage input/output algorithm. Trends in Amplification, 9(4), 159-197.

Shin, E. Y., Kim, D. Y., Park, H., Byun, H. M., Lee, S. M., Yoon, J. E., et al. (2008). Characteristics of loudness growth perception for Korean adults with normal hearing. Audiology, 4(1), 64-68.

Shin, S. \& Lee, K. (2017). Comparisons of sentence recognition scores and preferences according to compression types in a multi-channel hearing aid. Audiology and Speech Research, 13(1), 88-94.

Souza, P. E. (2002). Effects of compression on speech acoustics, intelligibility, and sound quality. Trends in Amplification, 6(4), 131-165.

Studebaker, G. A. \& Sherbecoe, R. L. (1991). Frequency-importance and transfer functions for recorded CID W-22 word lists. Journal of Speech, Language, and Hearing Research, 34(2), 427-438.

Studebaker, G. A., Sherbecoe, R. L., \& Gilmore, C. (1993). Frequency-importance and transfer functions for the auditec of St. Louis recordings of the NU-6 word test. Journal of Speech, Language, and Hearing Research, 36(4), 799-807.

Yasin, I. \& Plack, C. J. (2005). The role of suppression in the upward spread of masking. Journal of the Association for Research in Otolaryngology, 6(4), 368-377.

Yund, E. W. \& Buckles, K. M. (1995). Multichannel compression hearing aids: Effect of number of channels on speech discrimination in noise. The Journal of the Acoustical Society of America, 97(2), 1206-1223. 